\title{
Research on Domestic and Overseas Development Trend of Chinese Language and Literature
}

\author{
Lin Tian \\ Baotou Industry Vocational Technical College, 014035, China
}

Keywords: Chinese language, Domestic and overseas development, Literature, Development trend

\begin{abstract}
At first, the author makes an analysis on domestic and overseas development trend of Chinese language and literature. Based on historical background for construction of Chinese language and literature, the author also discusses principal issues and reasons for cultivation of applied talents in Chinese language and literature. At last, the author proposes relevant recommendations for improvement to cultivation of applied talents in Chinese language and literature, with expectations to provide certain reference to insiders.
\end{abstract}

\section{Domestic development trend of Chinese language and literature}

Major of Chinese language and literature is available in almost all colleges and universities in China. As a discipline with traditional color, Chinese language and literature plays an important role in cultivation of quality training in various colleges and universities. Development of Chinese language and literature in Chinese undergraduate colleges and universities can be summarized as three characteristics: long period, high level and standard pattern. In some Chinese colleges and universities, the orientation of senior secretary in Chinese language and literature generally stared from about 2000. A dozen of graduates cultivated met labor needs of relevant social positions with good reputation and outstanding performance. In lots of Chinese colleges and universities with Chinese language and literature available, most teachers are from the major of Chinese language and literature in famous comprehensive colleges and universities in China. These teachers have a solid literature foundation and systematic knowledge structure. Most Chinese teachers in domestic colleges and universities have teaching experiences in Chinese language and literature for almost ten years, for instance, Professor Shen Qi and Professor Ma Yuzhen. They play a critical role in cultivating talents in Chinese language and literature. In Chinese language and literature, the teaching atmosphere was gradually formed, which is led by professors and mainly composed of young teachers. However, the structure of teachers is also an important factor of talent cultivation, providing strong supports to amendment of Chinese language and literature talent cultivation program. It can be known by making a comparison of various famous colleges and universities about Chinese language and literature: while facing changes in social demands and deepening self education system, construction of Chinese language and literature also needs to persist in and carry forward humanistic education of Chinese language and literature, reform the talent cultivation pattern of Chinese language and literature under historical background, and finally realize the talent cultivation goal of thick foundation and wide caliper under multilevel and all-dimensional education scheme.

\section{Overseas development trend of Chinese language and literature}

Overseas literature development is resulted from professional scholars. Previously, most European scholars involved in the research of Oriental studies were customs officers, missionaries and diplomatic translators. They were not professional researchers of Oriental studies. Therefore, most Chinese language and literature works in the initial stage lack certain accuracy. At that time, most western sinologists ignored Chinese researchers and contemporary theoretical achievements. However, great masters of Paris School held opposite attitudes. Paris School was dissatisfied with existing researches, and promoted the research to deepen into China. At that time, European scholars held two kinds of attitude toward Sinology: the first kind is represented by France, regarding Chinese civilization as world civilization equal to Egypt, Greece and Roman. The second kind is represented 
by Britain and Germany, starting from respective politics and trade. Chavannes is the first person who made researches on ancient culture of China and contacted China. However, Pelliot had different cognition for Chinese studies when compared with most western rulers. Knowledgeable Pelliot is good at making good use of new materials to communicate between China and foreign countries on the basis of understanding the performance of Chinese scholars. In traditional history, document research is taken as the primary approach and other means as secondary approach. This mode of research is highlighted in China. This is also sourced from uninterrupted character culture of China, making references to be completely maintained. Thus, a prosperous situation was formed for academic traditional history of China. In modern China, new disciplines are also influenced to some extent. Archaeology takes verification and discovery of references as the emphasis, forming a distinctive contrast to European and American countries. Granet's attempt was also limited. At that time, some scholars used social background to explain individual psychology in French historian circle. Ge's family tried to take European feudal society as the object of research, but then changed to Chinese after finding insufficient historical materials. Chinese culture has a long history and the most persistence in world culture. Therefore, it agrees with this topic. Thus, it can be seen that: historical research of individual psychology explanation already reached a certain degree in France. In European Sinology circle, however, fewer scholars in typical Paris School researched individual psychology of Chinese literature and history. In France where Granet lived, sociology is close to ethnology. His social analysis method essentially belongs to the method of actual survey. Ge's family advocated taking rural culture in Zhengzhou of China as the research center. It was seldom influenced by urban culture. Then, Fei Xiaotong avoided for the first time the perplexity of reference. Research on rural society caused a sensation in educational circles. Imperial power and squire power were explained in combination with academic references in China.

\section{Historical background for construction of Chinese language and literature}

Once Chinese language and literature keeps away from the society, it will lack the most basic vitality. However, knowledge explanation is the major content of investigation for traditional knowledge talents after cultivation. The phenomenon of high scores and low abilities is resulted from taking notes in class, copying notes after class and reciting notes before examination. With era development, market posts require talents specialized in Chinese language and literature to acquire the ability to apply proper language for communication in PR planning and teaching negotiation, so as to discover the beauty of creation. In ancient China, there was a story about fighting against a million bold warriors with a silver tongue. It also proves important function of language. At present, it becomes more and more outstanding for the function of language in advertising and enterprise image design. It is imperative for the reform of classroom teaching concept of Chinese language and literature. Once the nature of language semiotics is acknowledged in professional teaching, its function will be no longer confined to the scope of tool. Ideological level of character will be represented. At present, the society has greater and greater demands for talents. At the same time, the society also proposes higher requirements for the quality of talents. Under new international situation, it is of great significance for Chinese language and literature to reform educational concept according to relevant laws of professional teaching. Only improvement based on competency-based education can radically improve the quality of school running. Practical value is served as a precondition for development. To make Chinese language and literature adapt to domestic and international situation in a better way, the author proposes relevant recommendations for the reform of traditional teaching mode and professional talent cultivation, so as to reach the effect of transiting from knowledge-based talents to competency-based talents. This is also an inevitable requirement of social development for traditional Chinese language and literature.

\section{Issues and reasons for applied talent cultivation in Chinese language and literature}

Relevant issues existing in the major of Chinese language are summarized as follows: the train of thought is not clear for the reform of talent cultivation pattern. Cognition lacks certain 
comprehensiveness. The training program is of great floatability. Curriculum setting fails to give full expression to development changes of Chinese language and literature in China and foreign countries. Applied educational concept is excessively stressed. Comprehensive quality and social adaptability of students are generally low, especially for undergraduates. Both level and field of employment are narrow. Therefore, it is of great significance for how to plan high-quality resources of Chinese Department as a whole and give play to advantages of diversified talents.

According to practical experiences in many years, to enhance literary attainment and humanistic quality of Chinese language is a general trend for domestic and overseas development. At the same time, it is also a basic requirement for undergraduate education as well as the reform orientation that must be determined with era development of Chinese language and literature. It can be known by making a comparison to domestic and overseas development of Chinese language and literature: many Chinese colleges and universities cultivate talents with high-strength applied competency from one side. Cultivation course of senior secretary mostly lays emphasis on practical skills of document writing. The time is reduced for basic course of Chinese language and literature. Consequently, talents cultivated by Chinese colleges and universities lack basic attainment. They are of inadequate inside information. Therefore, it is difficult for them to form continuous impetus. Quicker time aggravates the difficulty in keeping pace with the times. Therefore, talent cultivation of Chinese language and literature should be established on the basis of strong theoretical culture, gradually realize flexible migration of knowledge, and form professional vocational skills, so as to achieve the purpose of applied-oriented education.

The author revises by making a comparison of domestic and overseas development trend of Chinese language and literature. Based on the general rule for teaching development, the author makes corresponding improvement to the original talent cultivation pattern. While meeting basic theory learning, it also emphasizes the attention to curriculum application and skill. Thus, development demands of social posts can be satisfied to the maximum extent. At the same time, it can also help students to acquire a solid theoretical foundation and to form internal humanistic quality after mastering basic vocational skills. Additionally, new professional talents with innovation power and competitiveness are also served as the emphasis of program amendment. To have professional foundation of Chinese language, practical application ability and comprehensive humanistic quality is served as basic requirement for development of versatile talents in contemporary era.

\section{Strategies for cultivation of applied talents in Chinese language and literature}

\section{Adjustment to curriculum setting}

Emphasis on practice, solid foundation and wide caliper are three specifications for talent cultivation. Character of applied talents decides the fact that applied talents must have a wide foundation of theory and abundant professional theories. The significance of theory basic course is hereby embodied. It is unscientific to cut professional knowledge for the purpose of one-sided highlighting of application characteristics. In addition, training of students' application ability is also the emphasis of student cultivation of Chinese language and literature. In this link, the author mainly adopts basic course teaching to penetrate into application teaching, so as to make further improvement to students' operational ability. Enhancement of students' adaptation is helpful for their lifelong development. In a word, the achievement of the said goals needs to make amendment to training program. It is mainly embodied in adjustment to curriculum setting:

Standardization: it is mainly embodied in curriculum setting stipulated by the Ministry of Education. The major of Chinese language and literature can list all stipulated courses, making it clear for name and time. The author adopts the mode of changing introduction to foreign literature into history of foreign literature, further highlighting the cultivation emphasis of this course. For class hour, the author adopts history of foreign literature and history of classical Chinese literature to increase class hours of modern Chinese language.

Scientificity: it is mainly embodied in reference and quotation. Domestic colleges and universities can use for reference development experience of foreign Chinese language and literature. For 
instance, Northwest University, Sichuan University and Shaanxi Normal University have successful experiences in Chinese language talent cultivation program. Courses with unimportant relevance (such as advanced mathematics) can be canceled according to specific conditions. Aesthetics, Study of Chinese Classical Text and other courses can be quoted. The status of communication science and public relations as compulsory courses should be reconsidered. At the same time, class hours can be rearranged for basic Chinese language theory. Western literary criticism, Marxism-Leninism literary criticism, ancient Chinese literary theory and others are basic professional courses. Based on general teaching rules, foreign literature and modern Chinese language are ranked in front, and contemporary literature and ancient Chinese are arranged in the rear, so as to achieve the purpose of reasonable cohesion between course and course.

Systematicness: it is mainly embodied in detailed disciplinary levels, timeliness, profession, fundamentality, and improvement. We should combine Chinese literature with foreign literature and teacher specialty with professional cultivation. At the same time, we can also organically integrate western literature, oriental literature and comparative literature. Ancient literature can be divided into Confucius, Taoism, Tang poetry, Yuefu poetry, Song poems, fictions of the Ming and Qing dynasties and other elective courses.

Foresight: it is mainly embodied in the core of course and the leading role of textbook. Social development changes quickly with scientific and technological progress. It is of great significance to select course textbooks under the new situation. Textbooks can be recommended according to relevant departments, or self-compiled textbooks can be properly selected, so as to fully reflect cutting-edge theory of international Chinese language and literature, make timely research and tracking of recent news about domestic and overseas disciplinary development, and make subject to fully accord with market demands. For graduate school examination, for instance, it can be enhanced for learning of basic theory courses of Chinese language, making it convenient for students to have better competitiveness against students in other schools. For civil servant examination, more practical courses can be added on the basis of original applied writing, so as to promote students' continuous development with a long-term view.

\section{Adjustment to teaching content and mode}

According to the research on domestic and overseas development trend of Chinese language and literature, it is necessary to make adjustment to teaching contents in institutions of higher learning. Texts should be explained by using new historical values and knowledge. Moreover, we should also coordinate new teaching contents, making literature, language, writing and different courses to form emphasis points. Under the environment of seeking common points while reserving difference, we should also take cultivation of literary aesthetic ability as the core, and excavate internal potential according to personal character. Additionally, we should change traditional education and teaching mode, increase the interaction between students and teachers (mainly for the teaching pattern of “deciding everything by one man's say"), encourage students to raise innovative and curious questions, and develop students' artistic apperception ability by analyzing the problems. Sharp expression is quite helpful for students' wittiness competence. Students can be made to really experience the beauty of literature by always centering on independent thinking and creative thinking ability in talent cultivation of Chinese language and literature. At present, social development makes people to have higher requirements for language culture. The existence of special groups (such as the blind and the deaf-mute) also increases the difficulty of ideology in keeping pace with the times. Knowledge innovation is somewhat hindered. China enjoys a long history of Chinese language and a great space of development. Thousands of years of language culture essence can be inherited in a better way only by make continuous improvement in learning and defining the boundary of knowledge and ability based on practical demands of special work posts.

\section{Conclusion}

To sum up, it can be known from the research on domestic and overseas development trend of Chinese language and literature that the high realm of academy is essentially the same no matter for 
China or for foreign countries. the emphasis of the author's discussion lies on better processing of relevant issues about applied innovative talents of Chinese language and literature. With continuous development of the times, the development of Chinese language and literature will certainly present a series of new situations. At the same time, Chinese language and literature will also be confronted with challenges and opportunities. For radical promotion to the development of Chinese language and literature, it is necessary for relevant personnel to make great efforts.

\section{Acknowledgments}

This paper is a project of Baotou Science and Technology Bureau Intellectual Property: Research on Traditional Culture Education in Vocational Colleges (No.: 2012S2005-3).

\section{References}

[1] Cao Qiang, How Chinese Language and Literature can Make Response to Transformation Development Trend of Colleges and Universities - With Local Higher Education Institutions in Shaanxi Province as an Example, Shanxi Education (Higher Education Edition), 2014 (12);

[2] Zhou Xinghua, Reflection on Applicability of Chinese Language and Literature, Heilongjiang Researches on Higher Education, 2013 (01);

[3] Wang Juying, Wang Dejun and Guo Zhifeng, Response to the Challenge of Curriculum Reform of Elementary Education - Discussion on Chinese Language and Literature Curriculum and Teaching Reform in Higher Education Institutions, Journal of Tianshui Normal University, 2012 (06);

[4] Yin Jianxue, Assessment and Guidance for Basic Competence of Application-oriented Undergraduate Chinese Language and Literature, Vocational and Technical Education, 2014 (23);

[5] Su Zhaolong, Seek for Outlet of Chinese Language and Literature of Local Colleges and Universities in Employment Market, Research on Higher Education (Chengdu), 2011 (04);

[6] Shen Yongbao, Political Comments on One Hundred Years of Literature-Discussion on Political Comment Literature as the Origin of New Literature, Fudan Journal (Social Sciences Edition), 2013 (06) 